\title{
Coronary Microvascular Dysfunction is Common in Patients Hospitalized with COVID-19 Infection
}

\author{
Tolga Guvenc ${ }^{1}$
}

${ }^{1}$ Affiliation not available

July 26, 2021

Mustafa Çalı̧skan, MD ${ }^{\mathrm{a}}$; Ömer Faruk Baycan, MDª ; Fatma Betül Çelik, MD ${ }^{\mathrm{a}}$; Tolga Sinan Güvenç, $\mathrm{MD}^{\mathrm{b}}$; Adem Atıcı, MD ; Yasemin Çă̆, $\mathrm{MD}^{\mathrm{a}}$; Oğuz Konal, $\mathrm{MD}^{\mathrm{a}}$; Tuğçe İrgi, $\mathrm{MD}^{\mathrm{a}}$; Ümmühan Zeynep Bilgili, $\mathrm{MD}^{\mathrm{a}}$; Mehmet Ali Ağırbaşlı, MD

${ }^{a}$ Medeniyet University Faculty of Medicine, Department of Internal Medical Sciences, Division of Cardiology, Istanbul, Turkey

b Istinye University School of Medicine, Department of Internal Medical Sciences, Division of Cardiology, Istanbul, Turkey

Corresponding Author: Tolga Sinan Güvenç

Address for correspondence: Maltepe, İstinye Üniversitesi Topkapı Kampüsü, Teyyareci Sami Str. No.3, 34010 Zeytinburnu/İstanbul

Tel: 08502836000

Declarations of interest: none

\begin{abstract}
Background and aims: Myocardial injury is frequent in patients hospitalized with Sars-COV-2 infection and portents a worse prognosis, but the cause of myocardial injury is uncertain. Coronary microvascular dysfunction (CMD) has been hypothesized as a possible explanation, but direct evidence demonstrating CMD in COVID-19 patients is missing. In the present study, we aimed to investigate whether CMD is present in hospitalized COVID-19 patients, and to understand whether there is a relationship between biomarkers of myocardial injury, myocardial strain and inflammation and CMD in COVID-19 patients. Methods: 39 patients that were hospitalized with COVID-19 and 40 control subjects were included to the present study. Biomarkers for myocardial injury, myocardial strain, inflammation and fibrin turnover were obtained at admission. A comprehensive echocardiographic examination, including measurement of coronary flow velocity reserve (CFVR), were done after the patient was stabilized. Results: Patients with COVID-19 infection had a lower hyperemic coronary flow velocity, resulting in a significantly lower CFVR (2.0 \pm 0.3 vs. $2.4 \pm 0.5, \mathrm{p}<0.001)$. Patients with severe COVID-19 also had a lower CFVR compared to those with moderate COVID-19 (1.8 \pm 0.2 vs. $2.2 \pm 0.2, \mathrm{p}<0.001)$ due to an increase in basal flow velocity $(30.0 \pm 6.2$ vs. $26.0 \pm 4.8$, $\mathrm{p}=0.04)$. CFVR correlated with troponin $(\mathrm{p}=0.003, \mathrm{r}:-0.470)$, B-type natriuretic peptide $(\mathrm{p}<0.001, \mathrm{r}:-0.580)$, C-reactive protein $(\mathrm{p}<0.001, \mathrm{r}:-0.369)$, interleukin-6 ( $\mathrm{p}<0.001, \mathrm{r}:-0.597)$ and d-dimer $(\mathrm{p}<0.001, \mathrm{r}:-0.561)$, with the three latter biomarkers having the highest area-under-curve for predicting CMD. Conclusions: CMD is common in patients with COVID-19, and is related with the severity of the infection. CMD may also explain the "cryptic" myocardial injury seen in patients with severe COVID-19 infection.
\end{abstract}


Keywords: COVID-19; Sars-COV-2; coronary microvascular dysfunction; myocardial injury; echocardiography

\section{Introduction}

Sars-COV-2 is a novel betacoronavirus that have infected over 177 million individuals and claimed 3.9 million deaths globally $(1,2)$. Cardiac involvement in patients with moderate to severe COVID-19 infection could range from asymptomatic myocardial damage to overt myocarditis and myocardial infarction secondary to epicardial coronary artery disease (CAD) (3-7). Myocardial damage is somewhat common in patients hospitalized for COVID-19; while some cases can be explained with histologically proven myocarditis or epicardial CAD, in most cases the origin of this damage is uncertain (8). Coronary microvascular dysfunction has been suggested as a possible cause of myocardial ischemia in COVID-19 patients, as studies have suggested presence of microvascular dysfunction in other vascular beds and there is histologic evidence for Sars-COV-2 associated endothelitis in specimens obtained from heart, lung, kidney, liver and other tissues $(9,10)$. However, this is an indirect assumption as there are no data so far to suggest CMD in COVID-19 patients.

Cardiac microvascular dysfunction could be measured with several invasive or non-invasive methods (11-14). Coronary flow velocity reserve (CFVR), which can be obtained by comparing velocities obtained before and after administration of a vasodilator agent, is the primary method of assessing CMD with echocardiography. Importantly, echocardiography allows making bedside measurements, which is usually the optimal method for assessing CMD in critically ill patients.

In the present study, we aimed to understand whether patients hospitalized with COVID-19 had echocardiographically demonstrable CMD as compared to healthy individuals, and whether the severity of the disease correlates with the severity of CMD.

\section{Materials and Methods}

Present study is a cross-sectional case-control study performed in a single academic center. Patients aged between 20 and 60 years that were diagnosed with COVID-19 infection and hospitalized with this diagnosis were included. Patients that were past or current smokers, those with known coronary artery disease or diabetes, those with a history of heart failure due to any cause and patients on any kind of vasoactive drugs that might affect CFVR measurements were excluded. In addition, patients with a suboptimal image quality on echocardiography or patients with a condition that precluded administration of adenosine (such as asthma) were excluded. 50 COVID-19 patients were initially screened but 11 patients were excluded after applying these criteria. 40 age and gender matched subjects without a previous history of COVID-19, no active symptoms and had a negative nasopharyngeal swab for COVID-19 were enrolled as controls. Demographic, clinical and laboratory parameters were recorded with direct interviews and with using institutional electronic medical database.

The study was conducted according to the 1975 Helsinki and its subsequent revisions. All patients gave their informed consent, and the study was approved by a local ethics committee.

\section{Echocardiographic examination}

All echocardiographic examinations were performed with an ultrasound platform equipped with a matrixarray transducer (X5-1, Philips Epiq 7, Philips Healthcare, Andover, MA, USA). Chamber quantification and other measurements were done according to the relevant international guidelines. For coronary flow measurements, distal part of the left anterior descending artery (LAD) was visualized using high ultrasound beam frequency $(5-7 \mathrm{MHz})$. The color Doppler gain was optimized using conventional techniques and the Nyquist limit was set to $0.16-0.50 \mathrm{~m} / \mathrm{s}$. After visualization of the distal part of the LAD, pulse-wave Doppler cursor was placed to measure coronary flow velocity and measurements were done before and after dipyridamole infusion $(0.84 \mathrm{mg} / \mathrm{kg}$ for 6 minutes $)$. Patients were monitored during the procedure and heart rate and blood pressure data were recorded at baseline, during infusion and after the procedure. Coronary flow velocity reserve was calculated as the ratio of the hyperemic peak flow velocity to the resting peak flow 
velocity. We have previously reported interobserver and intraobserver variability values for our laboratory $(15,16)$.

All echocardiographic examinations, including CFVR measurements were performed immediately after the stabilization of the patient. For patients that needed intubation or intensive unit care due to any cause, echocardiographic examinations were delayed until the patient was transferred to the ward.

\section{Definition of moderate and severe COVID-19 infection}

All patients included in the present study had: i) A positive nasopharyngeal swab for COVID-19, ii) thoracic CT findings compatible with COVID-19 pneumonia and iii) hospitalized due to COVID-19 infection. Patients fulfilling one or more of the following criteria were accepted as severe COVID-19 infection: i) A respiratory rate $>30$ breaths/minute signifying respiratory distress, ii) a resting oxygen saturation $93 \%$ or less, iii) ratio of partial arterial oxygen saturation to the fraction of inspired oxygen $<300 \mathrm{mmHg}$ and iv) respiratory failure or a critical life-threatening complication of COVID-19 necessitating admission to intensive care unit. Patients who did not fulfill these criteria were accepted as having a moderate COVID-19 infection. Subjects within the control group had a negative nasopharyngeal swab for COVID-19, with or without a negative CT scan for COVID-19 pneumonia.

\section{Laboratory investigations}

Nasopharyngeal swabs were obtained at admission and COVID-19 infection was diagnosed with real time reverse-transcription PCR using Coronex COVID-19 rt-qPCR detection kit (Gensutek, Turkey). For all other tests, blood samples were obtained immediately after the diagnosis of COVID-19 was ascertained with a positive PCR test and a thorax CT scan compatible with COVID-19 pneumonia. Interleukin- 6 concentration was determined with electrochemiluminescence immunoassay method, using Elecsys IL-6 biochemical analysis kits and Roche Cobas 6000 analysis device (Roche Diagnostics, Basel, Switzerland). Other laboratory analyses were done with conventional methods.

\section{Statistical analyses}

Data for continuous parameters were given as mean \pm SD or median and interquartile range, depending on the distribution of the data. Categorical variables were presented as percentages. For continuous variables, patterns of distribution were analyzed with visual inspection of histograms and with Shapiro-Wilk test. Comparisons between groups were done with $\mathrm{T}$ test for independent samples or with Mann-Whitney U test as appropriate. For categorical variables, either $\chi^{2}$ test or Fisher's exact test were used to compare groups. Correlation analyses were done with Pearson test or with Spearman's rho. Finally, a receiver-operator curve was drawn to analyze the accuracy of various biomarkers to predict CMD, with the latter defined as a CFVR $<2.0$. For all analyses, $\mathrm{p}$ value less than 0.05 were accepted as statistically significant. All statistical analyses were done with SPSS 25.0 (IBM Inc, USA).

\section{Results}

Demographic, clinical and laboratory characteristics of the study groups were summarized in Table 1. COVID-19 (+) patients had a higher systolic and diastolic blood pressure and a lower oxygen saturation, as well as higher fibrinogen, ferritin and d-dimer concentrations at baseline. To note, there were no significant differences between patients in terms of age, gender, obesity, or other evaluated risk factors for atherosclerosis. Echocardiographic characteristics and coronary flow measurements of the study groups were summarized in Table 2. Conventional echocardiographic measurements were not different between groups, except for a significantly higher left atrial diameter in the COVID-19 (+) group. Basal coronary flow velocity was similar between groups, but hyperemic flow velocity was significantly lower in patients with COVID-19, leading to a statistically significant difference for CFVR between groups. Both basal and hyperemic heart rates were higher in the COVID-19 (+) group, but both findings did not reach statistical significance.

Patients with moderate and severe COVID-19 infection 
Patients with severe COVID-19 infection were more likely to have a higher respiratory rate, lower oxygen, and higher fibrinogen, troponin and BNP concentrations as compared to patients with moderate COVID19 infection (Table 3). Despite higher BNP or troponin concentrations, conventional echocardiographic parameters of left ventricular structure or systolic/diastolic functions were not different between groups. Basal coronary flow velocity was significantly higher and CFVR was significantly lower in patients with severe COVID-19, despite a lack of difference between groups in terms of hyperemic flow velocity reserve (Table 4). Neither basal nor hyperemic heart rate were different between groups, but there was a trend towards higher basal heart rate in severe COVID-19 patients.

\section{Relationships between CFVR and biomarkers}

CFVR showed a significant negative correlation with proinflammatory biomarkers, as well as with B-type natriuretic peptide (BNP), d-dimer and troponin. Of those, CFVR had a weak to moderate correlation with C-reactive protein $(\mathrm{p}<0.001, \mathrm{r}:-0.369)$, troponin $(\mathrm{p}=0.003, \mathrm{r}:-0.470)$ and white blood cell count $(\mathrm{p}=0.043$, r:-0.326); while it had a moderate to well correlation with BNP $(\mathrm{p}<0.001, \mathrm{r}:-0.580)$, interleukin-6 $(\mathrm{p}<0.001$, $\mathrm{r}:-0.597)$ and $\mathrm{d}$-dimer $(\mathrm{p}<0.001, \mathrm{r}:-0.561)$. Figure 1 summarizes correlations between CFVR and various biomarkers.

Of all biomarkers tested, fibrin-turnover marker d-dimer (AUC: $0.87(0.73-1.00), \mathrm{p}=0.001)$ had the highest accuracy for predicting CMD. For a cut-off value of 0.25 , d-dimer had a sensitivity of $90 \%$ and specificity of $70 \%$ to predict CMD. Inflammatory biomarkers C-reactive protein (AUC: $0.81(0.65-0.98), \mathrm{p}=0.004)$ and Interleukin-6 (AUC: 0.80 (0.62-0.97), $\mathrm{p}=0.008)$ also offered good predictive accuracies, with the former having a sensitivity of $95 \%$ and specificity of $60 \%$ for a cut-off value of $6.5 \mathrm{mg} / \mathrm{dl}$ and the latter had a sensitivity of $82 \%$ and specificity of $80 \%$ for a cut-off value of $13.9 \mathrm{pg} / \mathrm{ml}$. Other biomarkers with White blood cell count (AUC: $0.70(0.49-0.90), \mathrm{p}=0.07)$, BNP (AUC: $0.72(0.52-0.92), \mathrm{p}=0.042)$ and troponin (AUC: $0.72(0.52-$ $0.92), \mathrm{p}=0.042$ ) had smaller areas-under-curve to predict CMD (Figure 2).

\section{Discussion}

It has been suggested that COVID-19 is a disorder of the microvasculature. Given that microvascular dysfunction is seen in the subcutaneous and retinal vasculature in COVID-19 patients, several investigators have speculated that the same should also be true for the coronary microvasculature, but direct evidence was missing so far (17-20). Present study supports the validity of this latter hypothesis, since our findings indicate that CFVR, which is a measure of CMD, is lower in COVID-19 patients. Moreover, these findings also indicate a relationship between troponin and the degree of reduction in CFVR, thus providing a possible explanation for the "cryptic" troponin elevations in severe COVID-19 patients.

Several explanations have been offered to explain microvascular dysfunction in Sars-COV-2 infection. SarsCOV-2 gains access to cells by binding to the ACE2 receptor, which is expressed ubiquitously is many tissues $(21,22)$. There is histopathologic evidence to suggest that Sars-COV-2 infects endothelial cells and possibly inducing endothelial dysfunction $(23,24)$. There is also a well-known tendency towards thrombosis in patients with moderate-to-severe COVID-19 infection. Microvascular thrombosis and obstruction reduces recruitable capillaries, which in turn leads to microvascular dysfunction (25-27). Overactivation of inflammatory pathways with accompanying "cytokine storm", which is somewhat common in patients with severe COVID-19, can exacerbate endothelial dysfunction by either worsening endothelial inflammation or by activating prothrombotic cascades $(17,28)$. Probably not a single pathway is responsible for the development of CMD but rather all pathways are interwoven into each other, all of which ultimately leading to endothelial dysfunction and CMD.

Present observations are in line with the available evidence showing an abnormal capillary density and/or function in COVID-19 patients. Previous studies have suggested that COVID-19 patients have reduced flow reserve in the forearm skin, as well as reduced microcirculatory flow index and perfused vessel density in the sublingual circulation (29-31). Interestingly, in one of these observations Sabioni et al. have observed that peak hyperemic flow was impaired in either moderate or severe COVID-19 patients, but basal flow velocity was only affected in patients with severe COVID-19 (31). These findings were strikingly similar to the present 
results and suggests that small vessel disease is present in all COVID-19 patients with at least moderate disease (32). Moreover, our findings also demonstrated that CFVR is closely associated with biomarkers of fibrin turnover and inflammation, and thus suggesting that the aforementioned mechanisms could be responsible for CMD in COVID-19 patients. Theoretically, treatments aimed to disrupt the pathways of microvascular dysfunction, such as anticoagulants or anti-inflammatory agents, should improve microvascular dysfunction in those with moderate or severe COVID-19 infection, but this assumption needs further studies.

Troponin elevation is a common observation and a marker of worse prognosis in COVID-19 patients. Myocarditis was initially regarded as the most plausible cause of myocardial injury in the early stages of the pandemic, but histopathologic proof is scarce and is unlikely to explain the majority of cases (33). Other explanations, such as overt myocardial infarction or stress cardiomyopathy are usually self-evident and has other electrocardiographic and imaging findings that are not present in many cases with COVID-19 infection $(5,6,34)$. Although direct evidence was lacking, it has been long speculated that CMD could explain myocardial injury seen in severe COVID-19 patients $(15,20)$. Present findings indicate that the degree of CMD correlates with both troponin and B-type natriuretic peptide concentration, suggesting a relationship between CMD, myocardial injury and an increased left ventricular filling pressure. To note, correlation should not be interpreted as causality and all of these findings might simply represent the severity of the underlying disease rather than a causal association between CMD and myocardial damage. Present findings are nonetheless intriguing and warrants further search for a causal association between CMD and myocardial injury.

\section{Study Limitations}

This is a single-center study with a small sample size and a cross-sectional design. A variety of demographic conditions and diseases can affect CFVR, and while there were no significant differences between groups at baseline, such effects of confounders cannot be completely overruled. Biomarker concentrations were not obtained synchronously with the echocardiographic CFVR measurement in many patients. However, exposing a critically ill patient to a drug that could deteriorate her condition would be unethical, and an echocardiographic examination was performed as soon as possible. As correlation does not imply causality, present findings do not show that inflammation or prothrombotic milieu causes CFVR or CFVR leads to myocardial injury but rather suggests an association between them. Also, elevation of an inflammatory / thrombotic biomarker does not show an organ-specific condition but rather reflects an overall inflammatory or prothrombotic state. Thus, present findings should be interpreted in this context.

\section{Conclusions}

Patients with moderate to severe COVID-19 have a reduced hyperemic coronary flow and CFVR indicating presence of CMD. The degree of CMD correlates with biomarkers of inflammation, fibrin turnover, myocardial injury and myocyte stretch, though it remains to be determined whether these associations represent causal relationships between inflammation, thrombosis, microvascular dysfunction, and finally myocardial injury. Further work is needed to understand the clinical importance of these findings, as well as therapeutic approaches to prevent or treat CMD in COVID-19 patients.

\section{Author Contributions}

M.Ç and M.A.A. - study conception and design, critical review; Ö.F.B., F.B.Ç., A.A., Y.Ç., O.K., T.İ. and Ü.Z.B. - data acquisition and preparation of draft; T.S.G. - data interpretation, preparation of draft and final manuscript. All authors have approved the final version of the manuscript.

\section{Funding}

This research did not receive any specific grant from funding agencies in the public, commercial, or not-forprofit sectors.

\section{References}


1-) Hu B, Guo H, Zhou P, Shi ZL. Characteristics of SARS-CoV-2 and COVID-19. Nat Rev Microbiol. 2021;19:141-154. doi: 10.1038/s41579-020-00459-7.

2-) https://www.who.int/emergencies/diseases/novel-coronavirus-2019/situation-reports

3-) Shi S, Qin M, Shen B, Cai Y, Liu T, Yang F, et al. Association of Cardiac Injury With Mortality in Hospitalized Patients With COVID-19 in Wuhan, China. JAMA Cardiol. 2020;5:802-810. doi: 10.1001/jamacardio.2020.0950

4-) Caforio AL, Pankuweit S, Arbustini E, Basso C, Gimeno-Blanes J, Felix SB, et al. Current state of knowledge on aetiology, diagnosis, management, and therapy of myocarditis: a position statement of the European Society of Cardiology Working Group on Myocardial and Pericardial Diseases. Eur Heart J. 2013;34:2636-48, 2648a-2648d. doi: 10.1093/eurheartj/eht210.

5-) Modin D, Claggett B, Sindet-Pedersen C, Lassen MCH, Skaarup KG, Jensen JUS, et al. Acute COVID-19 and the Incidence of Ischemic Stroke and Acute Myocardial Infarction. Circulation. 2020;142:2080-2082. doi: 10.1161/CIRCULATIONAHA.120.050809.

6-) Bangalore S, Sharma A, Slotwiner A, Yatskar L, Harari R, Shah B, et al. ST-Segment Elevation in Patients with Covid-19 - A Case Series. N Engl J Med. 2020;382:2478-2480. doi: 10.1056/NEJMc2009020.

7-) Bilaloglu S, Aphinyanaphongs Y, Jones S, Iturrate E, Hochman J, Berger JS. Thrombosis in Hospitalized Patients With COVID-19 in a New York City Health System. JAMA. 2020;324:799-801. doi: 10.1001/jama.2020.13372.

8-) Sandoval Y, Januzzi JL Jr, Jaffe AS. Cardiac Troponin for Assessment of Myocardial Injury in COVID-19: JACC Review Topic of the Week. J Am Coll Cardiol. 2020;76:1244-1258. doi: 10.1016/j.jacc.2020.06.068.

9-) Fox SE, Lameira FS, Rinker EB, Vander Heide RS. Cardiac Endotheliitis and Multisystem Inflammatory Syndrome After COVID-19. Ann Intern Med. 2020;173:1025-1027. doi: 10.7326/L20-0882.

10-) Varga Z, Flammer AJ, Steiger P, Haberecker M, Andermatt R, Zinkernagel AS, et al. Endothelial cell infection and endotheliitis in COVID-19. Lancet. 2020; 395:1417-1418. doi: 10.1016/S0140-6736(20)30937-5.

11-) Barbato E, Aarnoudse W, Aengevaeren WR, Werner G, Klauss V, Bojara W, et al. Validation of coronary flow reserve measurements by thermodilution in clinical practice. Eur Heart J. 2004;25:219-23. doi: 10.1016/j.ehj.2003.11.009.

12-) Lanza GA, Buffon A, Sestito A, Natale L, Sgueglia GA, Galiuto L, et al. Relation between stress-induced myocardial perfusion defects on cardiovascular magnetic resonance and coronary microvascular dysfunction in patients with cardiac syndrome X. J Am Coll Cardiol. 2008;51:466-72. doi: 10.1016/j.jacc.2007.08.060.

13-) Murthy VL, Naya M, Taqueti VR, Foster CR, Gaber M, Hainer J, et al. Effects of sex on coronary microvascular dysfunction and cardiac outcomes. Circulation. 2014;129:2518-27. doi: 10.1161/CIRCULATIONAHA.113.008507.

14-) Galiuto L, Sestito A, Barchetta S, Sgueglia GA, Infusino F, La Rosa C, et al. Noninvasive evaluation of flow reserve in the left anterior descending coronary artery in patients with cardiac syndrome X. Am J Cardiol. 2007;99:1378-83. doi: 10.1016/j.amjcard.2006.12.070.

15-) Caliskan M, Turan Y, Caliskan Z, et al. Previous gestational diabetes history is associated with impaired coronary flow reserve. Ann Med. 2015;47:615-623. doi:10.3109/07853890.2015.1099719

16-) Ciftci FC, Caliskan M, Ciftci O, et al. Impaired coronary microvascular function and increased intimamedia thickness in preeclampsia. J Am Soc Hypertens. 2014;8:820-826. doi:10.1016/j.jash.2014.08.012

17-) Lowenstein CJ, Solomon SD. Severe COVID-19 Is a Microvascular Disease. Circulation. 2020;142:16091611. doi: 10.1161/CIRCULATIONAHA.120.050354. 
18-) Landecho MF, Yuste JR, Gándara E, Sunsundegui P, Quiroga J, Alcaide AB, et al. COVID-19 retinal microangiopathy as an in vivo biomarker of systemic vascular disease? J Intern Med. 2021;289:116-120. doi: 10.1111/joim.13156.

19-) Carsetti A, Damiani E, Casarotta E, Scorcella C, Domizi R, Montomoli J, et al. Sublingual microcirculation in patients with SARS-CoV-2 undergoing veno-venous extracorporeal membrane oxygenation. Microvasc Res. 2020;132:104064. doi: 10.1016/j.mvr.2020.104064.

20-) Yin J, Wang S, Liu Y, Chen J, Li D, Xu T. Coronary microvascular dysfunction pathophysiology in COVID-19. Microcirculation. 2021:e12718. doi: 10.1111/micc.12718.

21-) Hoffmann M, Kleine-Weber H, Schroeder S, Krüger N, Herrler T, Erichsen S, Schiergens TS, Herrler G, Wu NH, Nitsche A, Müller MA, Drosten C, Pöhlmann S. SARS-CoV-2 Cell Entry Depends on ACE2 and TMPRSS2 and Is Blocked by a Clinically Proven Protease Inhibitor. Cell. 2020;181:271-280.e8. doi: 10.1016/j.cell.2020.02.052.

22-) Hamming I, Timens W, Bulthuis ML, Lely AT, Navis G, van Goor H. Tissue distribution of ACE2 protein, the functional receptor for SARS coronavirus. A first step in understanding SARS pathogenesis. J Pathol. 2004;203:631-7. doi: 10.1002/path.1570.

23-) Varga Z, Flammer AJ, Steiger P, Haberecker M, Andermatt R, Zinkernagel AS, et al. Endothelial cell infection and endotheliitis in COVID-19. Lancet. 2020;395:1417-1418. doi: 10.1016/S0140-6736(20)30937-5.

24-) Bearse M, Hung YP, Krauson AJ, Bonanno L, Boyraz B, Harris CK, et al. Factors associated with myocardial SARS-CoV-2 infection, myocarditis, and cardiac inflammation in patients with COVID-19. Mod Pathol. 2021;34:1345-1357. doi: 10.1038/s41379-021-00790-1.

25-) Bösmüller H, Traxler S, Bitzer M, Häberle H, Raiser W, Nann D, et al. The evolution of pulmonary pathology in fatal COVID-19 disease: an autopsy study with clinical correlation. Virchows Arch. 2020;477:349357. doi: 10.1007/s00428-020-02881-x.

26-) Klok FA, Kruip MJHA, van der Meer NJM, Arbous MS, Gommers D, Kant KM, et al. Confirmation of the high cumulative incidence of thrombotic complications in critically ill ICU patients with COVID-19: An updated analysis. Thromb Res. 2020;191:148-150. doi: 10.1016/j.thromres.2020.04.041.

27-) O'Sullivan JM, Gonagle DM, Ward SE, Preston RJS, O'Donnell JS. Endothelial cells orchestrate COVID-19 coagulopathy. Lancet Haematol. 2020;7:e553-e555. doi: 10.1016/S2352-3026(20)30215-5.

28-) Karakike E, Giamarellos-Bourboulis EJ. Macrophage Activation-Like Syndrome: A Distinct Entity Leading to Early Death in Sepsis. Front Immunol. 2019;10:55. doi: 10.3389/fimmu.2019.00055.

29-) Abou-Arab O, Beyls C, Khalipha A, Guilbart M, Huette P, Malaquin S, et al. Microvascular flow alterations in critically ill COVID-19 patients: A prospective study. PLoS One. 2021;16:e0246636. doi: 10.1371/journal.pone.0246636.

30-) Tehrani S, Gille-Johnson P. Microvascular Dysfunction in Patients with Critical COVID-19, A Pilot Study. Shock. 2021 May 4. doi: 10.1097/SHK.0000000000001803.

31-) Sabioni L, De Lorenzo A, Lamas C, Muccillo F, Castro-Faria-Neto HC, Estato V, et al. Systemic microvascular endothelial dysfunction and disease severity in COVID-19 patients: Evaluation by laser Doppler perfusion monitoring and cytokine/chemokine analysis. Microvasc Res. 2021;134:104119. doi: 10.1016/j.mvr.2020.104119.

32-) Hoffman JI. Problems of coronary flow reserve. Ann Biomed Eng. 2000 Aug;28(8):884-96. doi: 10.1114/1.1308503. PMID: 11144672.

33-) Escher F, Pietsch H, Aleshcheva G, Bock T, Baumeier C, Elsaesser A, et al. Detection of viral SARSCoV-2 genomes and histopathological changes in endomyocardial biopsies. ESC Heart Fail. 2020;7:2440-2447. doi: $10.1002 /$ ehf2.12805. 
34-) Park JH, Moon JY, Sohn KM, Kim YS. Two Fatal Cases of Stress-induced Cardiomyopathy in COVID19 Patients. J Cardiovasc Imaging. 2020;28:300-303. doi: 10.4250/jcvi.2020.0125.

\section{Figure Legends}

Figure 1. Scatter plots showing correlations between coronary flow velocity reserve and B-type natriuretic peptide (top left), troponin (top right), d-dimer (bottom right) and interleukin-6 (bottom left). BNP: B-type natriuretic peptide.

Figure 2. Receiver-operator curves showing accuracy for various biomarkers to predict coronary microvascular dysfunction. Lines were color-coded and references for lines were provided on the top right. Diagonal line shows reference. BNP: B-type natriuretic peptide, IL-6: Interleukin-6, CRP: C-reactive protein, WBC: White blood cell count.

Table 1. Demographic, clinical and laboratory characteristics of subjects with and without COVID-19 infection

\begin{tabular}{lllll}
\hline Characteristic & COVID-19 $(+)(n=39)$ & COVID-19 $(-)(n=40)$ & COVID-19 (-) $(n=40)$ & COVID-19 (-) \\
\hline Age, years & $42.5 \pm 7.8$ & $42.5 \pm 7.8$ & $41.1 \pm 4.8$ & 0.337 \\
Male, $\mathrm{n}(\%)$ & $24(61)$ & $24(61)$ & $22(55)$ & 0.556 \\
$\mathrm{BMI}, \mathrm{kg} / \mathrm{m}^{2}$ & $28.1 \pm 4.3$ & $28.1 \pm 4.3$ & $27.0 \pm 3.2$ & 0.223 \\
$\mathrm{Hyp}$ & $3(7)$ & $3(7)$ & $4(10)$ & 0.718 \\
$\mathrm{SAP},(\mathrm{mmHg})$ & $125.7 \pm 9.2$ & $125.7 \pm 9.2$ & $118.6 \pm 10.1$ & 0.002 \\
$\mathrm{DAP},(\mathrm{mmHg})$ & $82.4 \pm 7.8$ & $82.4 \pm 7.8$ & $75.3 \pm 5.8$ & $<0.001$ \\
$\mathrm{RR}(/ \mathrm{min})$ & $21.2 \pm 3.8$ & $21.2 \pm 3.8$ & $17.5 \pm 2.6$ & $<0.001$ \\
$\mathrm{sO}(\%)$ & $90.1 \pm 5.7$ & $90.1 \pm 5.7$ & $97.7 \pm 1.9$ & $<0.001$ \\
$\mathrm{Albumin}(\mathrm{g} / \mathrm{dL})$ & $3.4 \pm 0.4$ & $3.4 \pm 0.4$ & $3.7 \pm 0.4$ & 0.005 \\
$\mathrm{AST}(\mathrm{IU} / \mathrm{L})$ & $31(24-52)$ & $31(24-52)$ & $28(21-32)$ & 0.043 \\
$\mathrm{ALT}(\mathrm{IU} / \mathrm{L})$ & $27(18-41)$ & $27(18-41)$ & $22(18-32)$ & 0.035 \\
$\mathrm{CRP}(\mathrm{mg} / \mathrm{dL})$ & $19(9-60)$ & $19(9-60)$ & $3(0-7)$ & $<0.001$ \\
Glucose $(\mathrm{mg} / \mathrm{dL})$ & $124.5 \pm 45.1$ & $124.5 \pm 45.1$ & $95.4 \pm 23.4$ & 0.001 \\
Creatinine $(\mathrm{mg} / \mathrm{dL})$ & $0.8 \pm 0.2$ & $0.8 \pm 0.2$ & $0.8 \pm 0.2$ & 0.690 \\
GFR $\left(\mathrm{ml} / \mathrm{min} / 1.73 \mathrm{~m}{ }^{2}\right)$ & $98.6 \pm 18.9$ & $98.6 \pm 18.9$ & $100.5 \pm 18.6$ & 0.671 \\
Uric Acid $(\mathrm{mg} / \mathrm{dL})$ & $4.0 \pm 1.4$ & $4.0 \pm 1.4$ & $4.1 \pm 1.4$ & 0.857 \\
WBC count $\left(10^{3} / \mu l\right)$ & $7.1 \pm 3.2$ & $7.1 \pm 3.2$ & $6.7 \pm 1.7$ & 0.552 \\
Hemoglobin $(\mathrm{g} / \mathrm{dl})$ & $13.3 \pm 1.8$ & $13.3 \pm 1.8$ & $12.8 \pm 1.2$ & 0.203 \\
Platelet count $\left(10^{3} / \mu \mathrm{L}\right)$ & $226.2 \pm 69.4$ & $226.2 \pm 69.4$ & $217.6 \pm 68.1$ & 0.580 \\
TC $(\mathrm{mg} / \mathrm{dL})$ & $156.1 .0 \pm 32.0$ & $156.1 .0 \pm 32.0$ & $191.5 \pm 31.4$ & $<0.001$ \\
LDL $(\mathrm{mg} / \mathrm{dL})$ & $87.9 \pm 24.1$ & $87.9 \pm 24.1$ & $118.8 \pm 26.9$ & $<0.001$ \\
HDL $(\mathrm{mg} / \mathrm{dL})$ & $39.1 \pm 9.8$ & $39.1 \pm 9.8$ & $44.0 \pm 8.0$ & 0.017 \\
Triglycerides $(\mathrm{mg} / \mathrm{dL})$ & $135.9 \pm 57.3$ & $135.9 \pm 57.3$ & $136.4 \pm 50.4$ & 0.967 \\
Fibrinogen $(\mathrm{mg} / \mathrm{dL})$ & $610.5 \pm 156.2$ & $610.5 \pm 156.2$ & $277.3 \pm 48.3$ & $<0.001$ \\
Ferittin $(\mathrm{ng} / \mathrm{mL})$ & $486(83-994)$ & $486(83-994)$ & $83(55-286)$ & $<0.001$ \\
D-dimer $(\mu \mathrm{m} / \mathrm{mL})$ & $1.0(0.7-1.5)$ & $1.0(0.7-1.5)$ & $0.5(0.2-0.6)$ & $<0.001$ \\
\hline
\end{tabular}

BMI, body mass index; HT, hypertension; SAP, systolic arterial pressure; DAP, diastolic arterial pressure; $\mathrm{RR}$, respiratory rate; $\mathrm{sO}_{2}$, saturation oxygen; AST, aspartate aminotransferase; ALT, alanine aminotransferase; CRP, C-reactive protein; GFR, glomerular filtration rate; WBC, white blood cell; TC, total cholesterol; LDL, low-density lipoprotein; HDL, high-density lipoprotein.

Table 2. Echocardiographic characteristics of subjects with and without COVID-19 infection 


\begin{tabular}{lllll}
\hline Characteristic & COVID-19 $(+)(n=39)$ & COVID-19 $(-)(n=40)$ & COVID-19 $(-)(n=40)$ & COVID-19 $(-)$ \\
\hline LVEF (\%) & $61.5 \pm 7.4$ & $61.5 \pm 7.4$ & $64.0 \pm 2.5$ & 0.057 \\
LVDD (mm) & $46.0 \pm 3.3$ & $46.0 \pm 3.3$ & $45.3 \pm 3.2$ & 0.325 \\
LVSD (mm) & $28.1 \pm 3.1$ & $28.1 \pm 3.1$ & $27.8 \pm 2.8$ & 0.633 \\
IVS (cm) & $0.9 \pm 0.1$ & $0.9 \pm 0.1$ & $0.9 \pm 0.1$ & 0.235 \\
PW (cm) & $0.9 \pm 0.1$ & $0.9 \pm 0.1$ & $0.9 \pm 0.1$ & 0.851 \\
AoD (cm) & $3.0 \pm 0.4$ & $3.0 \pm 0.4$ & $3.2 \pm 0.3$ & 0.031 \\
LA $(\mathrm{cm})$ & $3.5 \pm 0.3$ & $3.5 \pm 0.3$ & $3.0 \pm 0.4$ & $<0.001$ \\
Mitral E wave (m/s) & $0.8 \pm 0.1$ & $0.8 \pm 0.1$ & $0.8 \pm 0.1$ & 0.303 \\
Mitral A wave (m/s) & $0.7 \pm 0.1$ & $0.7 \pm 0.1$ & $0.6 \pm 0.1$ & 0.230 \\
Mitral IVRT (ms) & $88.6 \pm 16.5$ & $88.6 \pm 16.5$ & $86.0 \pm 16.8$ & 0.485 \\
Septal E wave (cm/s) & $9.8 \pm 1.8$ & $9.8 \pm 1.8$ & $10.5 \pm 2.4$ & 0.183 \\
Lateral E wave (cm/s) & $14.4 \pm 3.0$ & $14.4 \pm 3.0$ & $14.8 \pm 2.7$ & 0.504 \\
Tricuspid S wave (cm/s) & $12.8 \pm 2.3$ & $12.8 \pm 2.3$ & $13.2 \pm 2.8$ & 0.55 \\
TAPSE (cm) & $2.3 \pm 0.3$ & $2.3 \pm 0.3$ & $2.4 \pm 0.3$ & 0.050 \\
Basal DPFV (m/s) & $28.4 \pm 6.0$ & $28.4 \pm 6.0$ & $27.9 \pm 5.7$ & 0.658 \\
Hyperemic DPFV (m/s) & $56.8 \pm 12.1$ & $56.8 \pm 12.1$ & $66.9 \pm 15.5$ & 0.002 \\
CFVR & $2.0 \pm 0.3$ & $2.0 \pm 0.3$ & $2.4 \pm 0.5$ & $<0.001$ \\
Basal HR (bpm) & $75.3 \pm 8.5$ & $75.3 \pm 8.5$ & $72.4 \pm 7.9$ & 0.118 \\
Hyperemic HR (bpm) & $99.7 \pm 10.0$ & $99.7 \pm 10.0$ & $95.6 \pm 11.3$ & 0.089 \\
\hline
\end{tabular}

LVEF, left ventricular ejection fraction; LVDD, left ventricular diastolic diameter; LVSD, left ventricular systolic diameter; IVS, interventricular septum; PW, posterior wall; AoD, aortic diameter; LA, left atrium; IVRT, interventricular relaxation time; TAPSE, tricuspid annular plane systolic excursion; DPFV, diastolic pressure flow velocity; CFVR, coronary flow velocity reserve; HR, heart rate.

Table 3. Demographic, clinical and laboratory characteristics of patients wth moderate and severe COVID-19 infection

\begin{tabular}{llllll}
\hline Characteristic & Severe $(n=24)$ & Moderate $(n=15)$ & Moderate $(n=15)$ & Moderate $(n=15)$ & $p$ \\
\hline Age, years & $42.9 \pm 8.1$ & $42.9 \pm 8.1$ & $41.9 \pm 7.5$ & 0.709 & 0.709 \\
Male, $\mathrm{n}(\%)$ & $17(70)$ & $17(70)$ & $7(46)$ & 0.131 & 0.131 \\
$\mathrm{BMI}, \mathrm{kg} / \mathrm{m}^{2}$ & $27.7 \pm 4.5$ & $27.7 \pm 4.5$ & $28.6 \pm 4.1$ & 0.529 & 0.529 \\
$\mathrm{SAP},(\mathrm{mmHg})$ & $124.6 \pm 9.2$ & $124.6 \pm 9.2$ & $127.5 \pm 9.3$ & 0.348 & 0.348 \\
$\mathrm{DAP},(\mathrm{mmHg})$ & $81.5 \pm 8.4$ & $81.5 \pm 8.4$ & $83.8 \pm 6.8$ & 0.390 & 0.390 \\
$\mathrm{RR}$ & $23.0 \pm 3.8$ & $23.0 \pm 3.8$ & $18.3 \pm 1.5$ & $<0.001$ & $<0.001$ \\
$\mathrm{sO}{ }_{2}$ & $86.8 \pm 4.8$ & $86.8 \pm 4.8$ & $95.5 \pm 1.7$ & $<0.001$ & $<0.001$ \\
Albumin $(\mathrm{g} / \mathrm{dL})$ & $3.3 \pm 0.3$ & $3.3 \pm 0.3$ & $3.6 \pm 0.3$ & 0.022 & 0.022 \\
$\mathrm{AST}(\mathrm{IU} / \mathrm{L})$ & $31(27-50)$ & $31(27-50)$ & $30(20-65)$ & 0.786 & 0.786 \\
$\mathrm{ALT}(\mathrm{IU} / \mathrm{L})$ & $25(18-44)$ & $25(18-44)$ & $27(18-41)$ & 0.989 & 0.989 \\
$\mathrm{CRP}(\mathrm{mg} / \mathrm{dL})$ & $37(10-88)$ & $37(10-88)$ & $11(5-30)$ & 0.017 & 0.017 \\
Glucose $(\mathrm{mg} / \mathrm{dL})$ & $139.5 \pm 49.6$ & $139.5 \pm 49.6$ & $100.6 \pm 22.0$ & 0.007 & 0.007 \\
Creatinine $(\mathrm{mg} / \mathrm{dL})$ & $0.8 \pm 0.1$ & $0.8 \pm 0.1$ & $0.8 \pm 0.2$ & 0.456 & 0.456 \\
GFR $\left(\mathrm{ml} / \mathrm{dk} / \mathrm{l} .73 \mathrm{~m}{ }^{2}\right)$ & $99.9 \pm 14.9$ & $99.9 \pm 14.9$ & $96.7 \pm 24.6$ & 0.617 & 0.617 \\
Uric acid $(\mathrm{mg} / \mathrm{dL})$ & $3.9 \pm 1.2$ & $3.9 \pm 1.2$ & $4.2 \pm 1.6$ & 0.545 & 0.545 \\
WBC count $\left(10^{3} / \mu \mathrm{l}\right)$ & $7.7 \pm 3.8$ & $7.7 \pm 3.8$ & $6.1 \pm 1.7$ & 0.140 & 0.140 \\
Haemoglobin $(\mathrm{g} / \mathrm{dL})$ & $13.4 \pm 2.0$ & $13.4 \pm 2.0$ & $13.1 \pm 1.3$ & 0.651 & 0.651 \\
Platelet count $\left(10^{3} / \mu \mathrm{L}\right)$ & $241.7 \pm 73.4$ & $241.7 \pm 73.4$ & $201.4 \pm 56.3$ & 0.078 & 0.078 \\
TC $(\mathrm{mg} / \mathrm{dL})$ & $151.4 \pm 24.3$ & $151.4 \pm 24.3$ & $163.7 \pm 41.4$ & 0.250 & 0.250 \\
LDL $(\mathrm{mg} / \mathrm{dL})$ & $84.9 \pm 21.0$ & $84.9 \pm 21.0$ & $92.8 \pm 28.4$ & 0.330 & 0.330
\end{tabular}




\begin{tabular}{llllll}
\hline Characteristic & Severe $(n=24)$ & Moderate $(n=15)$ & Moderate $(n=15)$ & Moderate $(n=15)$ & $p$ \\
\hline HDL $(\mathrm{mg} / \mathrm{dL})$ & $39.2 \pm 11.3$ & $39.2 \pm 11.3$ & $38.8 \pm 7.4$ & 0.898 & 0.898 \\
Triglycerides $(\mathrm{mg} / \mathrm{dL})$ & $136.0 \pm 56.9$ & $136.0 \pm 56.9$ & $135.7 \pm 60.1$ & 0.987 & 0.987 \\
Fibrinogen $(\mathrm{mg} / \mathrm{dL})$ & $657.5 \pm 133.5$ & $657.5 \pm 133.5$ & $535.2 \pm 164.6$ & 0.015 & 0.015 \\
Ferittin $(\mathrm{ng} / \mathrm{mL})$ & $614(132-994)$ & $614(132-994)$ & $210(66-914)$ & 0.851 & 0.851 \\
D-dimer $(\mu \mathrm{g} / \mathrm{mL})$ & $1.2(0.7-1.7)$ & $1.2(0.7-1.7)$ & $1.0(0.7-1.4)$ & 0.415 & 0.415 \\
BNP $(\mathrm{pg} / \mathrm{mL})$ & $186(75-245)$ & $186(75-245)$ & $29(10-179)$ & 0.006 & 0.006 \\
Troponin $(\mathrm{ng} / \mathrm{mL})$ & $10(9-25)$ & $10(9-25)$ & $10(0-10)$ & 0.010 & 0.010 \\
IL-6 $(\mathrm{pg} / \mathrm{mL})$ & $22(12-31)$ & $22(12-31)$ & $8(5-32)$ & 0.182 & 0.182 \\
ICU admission, $\mathrm{n}(\%)$ & $3(12)$ & $3(12)$ & $0(0)$ & 0.271 & 0.271 \\
MV, $\mathrm{n}(\%)$ & $2(8)$ & $2(8)$ & $0(0)$ & 0.514 & 0.514 \\
NIMV, $\mathrm{n}(\%)$ & $3(12)$ & $3(12)$ & $0(0)$ & 0.271 & 0.271 \\
Lopinavir/Ritonavir, $\mathrm{n}(\%)$ & $16(66)$ & $16(66)$ & $4(26)$ & 0.022 & 0.022 \\
Other antiviral, $\mathrm{n}(\%)$ & $22(92)$ & $22(92)$ & $13(87)$ & 0.793 & 0.793 \\
Immune modulators, $\mathrm{n}(\%)$ & $23(96)$ & $23(96)$ & $7(47)$ & 0.001 & 0.001 \\
\hline
\end{tabular}

BMI, body mass index; HT, hypertension; DM, diabetes mellitus; SAP, systolic arterial pressure; DAP, diastolic arterial pressure; $\mathrm{RR}$, respiratory rate; $\mathrm{sO}_{2}$, saturation oxygen; AST, aspartat aminotransferaz; ALT, alanin aminotransferaz; CRP, C-reactive protein; GFR, glomerular filtration rate; WBC, white blood cell; TC, total cholesterol; LDL, low-density lipoprotein; HDL, high-density lipoprotein; BNP, brain natriuretic peptide; IL, interleukin; ICU, intensive care unit; MV, mechanical ventilation; NIMV, noninvasive mechanical ventilation.

Table 4. Echocardiographic characteristics of patients with moderate and severe COVID-19 infection

\begin{tabular}{llllll}
\hline Characteristic & Severe $(n=24)$ & Non-severe $(n=15)$ & Non-severe $(n=15)$ & Non-severe $(n=15)$ & $p$ \\
\hline LVEF (\%) & $61.4 \pm 7.4$ & $61.4 \pm 7.4$ & $61.6 \pm 7.7$ & 0.934 & 0.934 \\
LVDD (mm) & $46.5 \pm 3.1$ & $46.5 \pm 3.1$ & $45.2 \pm 3.6$ & 0.218 & 0.218 \\
LVSD (mm) & $28.8 \pm 2.8$ & $28.8 \pm 2.8$ & $27.0 \pm 3.2$ & 0.095 & 0.095 \\
IVS (cm) & $0.9 \pm 0.1$ & $0.9 \pm 0.1$ & $0.8 \pm 0.1$ & 0.489 & 0.489 \\
PW (cm) & $0.8 \pm 0.0$ & $0.8 \pm 0.0$ & $0.8 \pm 0.1$ & 0.464 & 0.464 \\
AoD (cm) & $3.0 \pm 0.4$ & $3.0 \pm 0.4$ & $2.9 \pm 0.3$ & 0.637 & 0.637 \\
LA (cm) & $3.5 \pm 0.3$ & $3.5 \pm 0.3$ & $3.4 \pm 0.3$ & 0.571 & 0.571 \\
Mitral E wave (m/s) & $0.8 \pm 0.1$ & $0.8 \pm 0.1$ & $0.7 \pm 0.1$ & 0.721 & 0.721 \\
Mitral A wave (cm/s) & $0.6 \pm 0.1$ & $0.6 \pm 0.1$ & $0.7 \pm 0.2$ & 0.256 & 0.256 \\
Mitral IVRT (ms) & $87.1 \pm 17.9$ & $87.1 \pm 17.9$ & $91.2 \pm 14.2$ & 0.462 & 0.462 \\
Septal E wave (cm/s) & $9.8 \pm 1.7$ & $9.8 \pm 1.7$ & $9.8 \pm 2.0$ & 0.990 & 0.990 \\
Lateral E wave (cm/s) & $14.0 \pm 2.9$ & $14.0 \pm 2.9$ & $14.9 \pm 3.2$ & 0.406 & 0.406 \\
Tricuspid S wave $(\mathrm{cm} / \mathrm{s})$ & $13.3 \pm 2.3$ & $13.3 \pm 2.3$ & $12.0 \pm 2.2$ & 0.121 & 0.121 \\
TAPSE (cm) & $2.3 \pm 0.3$ & $2.3 \pm 0.3$ & $2.2 \pm 0.3$ & 0.494 & 0.494 \\
Basal DPFV (m/s) & $30.0 \pm 6.2$ & $30.0 \pm 6.2$ & $26.0 \pm 4.8$ & 0.040 & 0.040 \\
Hyperemic DPFV $(\mathrm{m} / \mathrm{s})$ & $55.2 \pm 12.5$ & $55.2 \pm 12.5$ & $59.3 \pm 11.5$ & 0.316 & 0.316 \\
CFVR & $1.8 \pm 0.2$ & $1.8 \pm 0.2$ & $2.2 \pm 0.2$ & $<0.001$ & $<0.001$ \\
Basal HR (bpm) & $77.2 \pm 9.2$ & $77.2 \pm 9.2$ & $72.2 \pm 6.3$ & 0.073 & 0.073 \\
Hyperemic HR (bpm) & $101.2 \pm 9.5$ & $101.2 \pm 9.5$ & $97.4 \pm 10.5$ & 0.247 & 0.247 \\
\hline
\end{tabular}

LVEF, left ventricular ejection fraction; LVDD, left ventricular diastolic diameter; LVSD, left ventricular systolic diameter; IVS, interventricular septum; PW, posterior wall; AoD, aortic diameter; LA, left atrium; 
IVRT, interventricular relaxation time; TAPSE, tricuspid annular plane systolic excursion; DPFV, diastolic pressure flow velocity; CFVR, coronary flow velocity reserve; HR, heart rate. 